\title{
AN INITIAL ASSESSMENT OF POTENTIAL \\ PRODUCTION \\ TECHNOLOGIES FOR \\ EPSILON-METAL WASTE \\ FORMS
}

Fuel Cycle Research \& Development

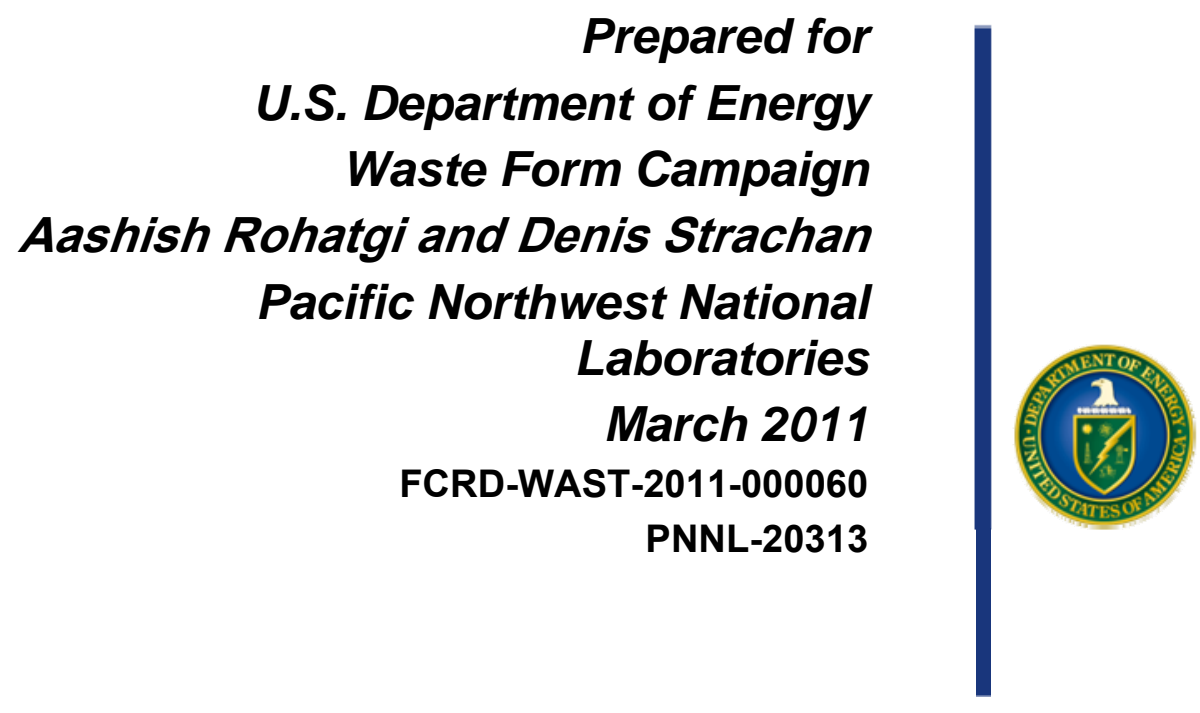




\section{DISCLAIMER}

This information was prepared as an account of work sponsored by an agency of the U.S. Government. Neither the U.S. Government nor any agency thereof, nor any of their employees, makes any warranty, expressed or implied, or assumes any legal liability or responsibility for the accuracy, completeness, or usefulness, of any information, apparatus, product, or process disclosed, or represents that its use would not infringe privately owned rights. References herein to any specific commercial product, process, or service by trade name, trade mark, manufacturer, or otherwise, does not necessarily constitute or imply its endorsement, recommendation, or favoring by the U.S. Government or any agency thereof. The views and opinions of authors expressed herein do not necessarily state or reflect those of the U.S. Government or any agency thereof. 


\section{SUMMARY}

This report examines and ranks seven materials processing techniques that may be used to consolidate the undissolved solids, reduced soluble technetium, and soluble noble metals from nuclear fuel reprocessing into a low-surface area waste form. Commercial vendors of processing equipment were contacted and literature researched to gather information for this report. Typical equipment and their operation, corresponding to each of the seven techniques, are described in the report based upon the discussions and information provided by the vendors. Although the report does not purport to describe all the capabilities and issues of various consolidation techniques, it is anticipated that this report will serve as a guide by highlighting the key advantages and disadvantages of these techniques.

The processing techniques described in this report were broadly classified into those that employed melting and solidification, and those in which the consolidation takes place in the solid-state. Four additional techniques were examined that were deemed impractical, but were included for completeness. The techniques were ranked based on criteria such as flexibility in accepting wide-variety of feed-stock (chemistry, form, and quantity), ease of maintenance, hot cell space requirements, generation of additional waste streams, cost, and any special considerations. Based on the assumption of $\sim 2.5 \mathrm{~L}$ of waste to be consolidated per day, sintering based techniques, namely, microwave sintering, spark plasma sintering and hot isostatic pressing, were ranked as the top-3 choices, respectively. Melting and solidification based techniques were ranked lower on account of generation of volatile phases and difficulties associated with reactivity and containment of the molten metal. 


\section{CONTENTS}

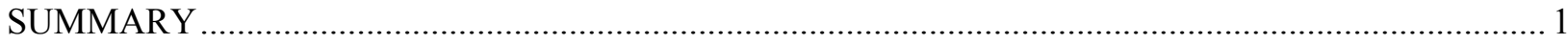

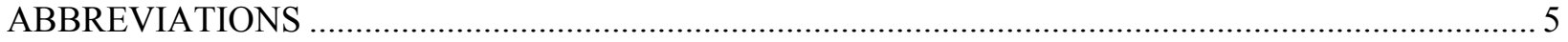

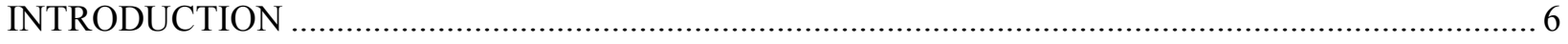

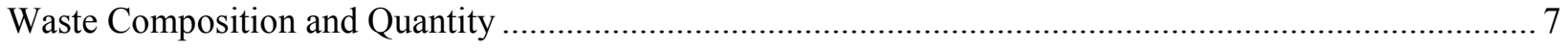

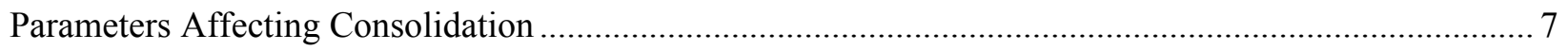

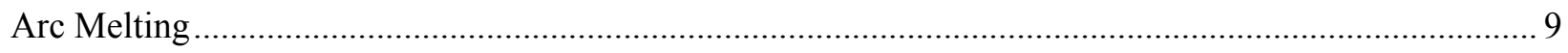

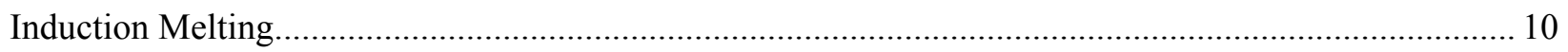

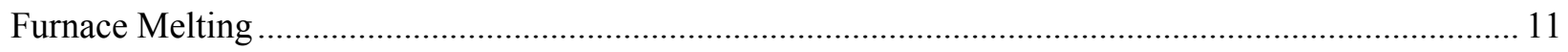

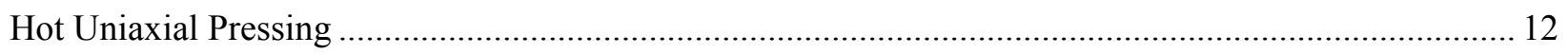

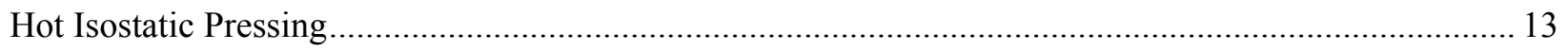

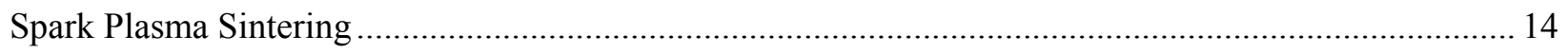

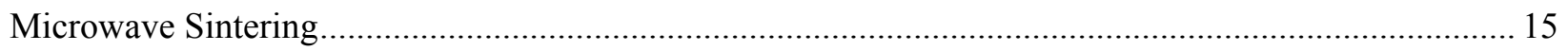

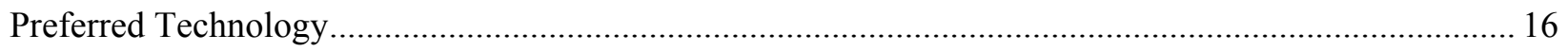

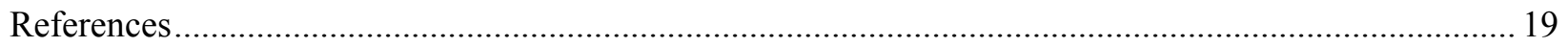

Appendix A TECHNIQUES THAT WERE NOT CONSIDERED .................................................... 20

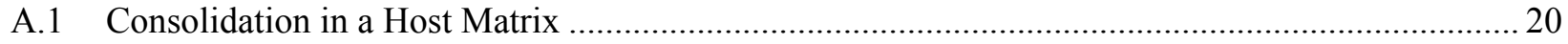

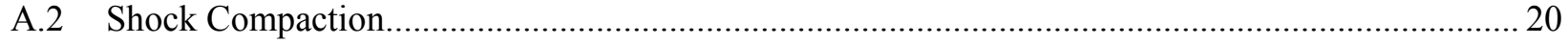

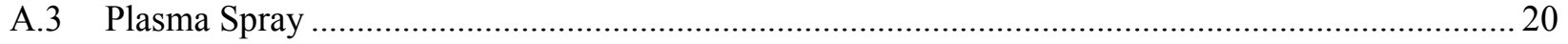

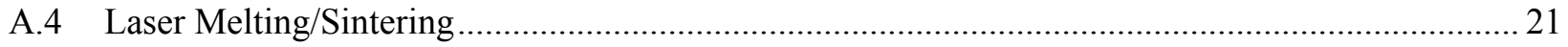




\section{FIGURES}

Figure 1. Cylindrical ingot size (diameter and height) and quantity for $2.5 \mathrm{~L} / \mathrm{d}$ of $\varepsilon$-metal plus recycled Tc and noble metals. 8

Figure 2. Single-torch plasma arc furnace by Retech Systems, LLC (Ukiah, CA). 9

Figure 3. Induction heating system, model Ekoheat by Ameritherm, Inc (Ambrell/Ameritherm Inc. 2010). 10

Figure 4. A front loaded high-temperature furnace (Model 121212 by Thermal Technology (Thermal Technology LLC 2010b))

Figure 5. Hot uniaxial press (Model Hot Press-25 tons by Thermal Technology (Thermal Technology LLC 2010a)). 12

Figure 6. Hot isostatic press (HIP) system (Model Mini-HIPper QIH-15e, by Avure Technologies (Avure Technologies 2010)). 13

Figure 7. Spark plasma sintering system (Model SPS-25-10 by Thermal Technology LLC (Thermal Technology LLC 2010b)).

Figure 8. Microwave high-temperature furnace system, (Model HAMiLab-V6 by Spheric Technologies, Inc. (Spheric Technologies Inc. 2010)). 15 
TABLES

Table 1. Key thermal properties and the quantities of UDS and $\varepsilon$-Metal per MTIHM for two fuel

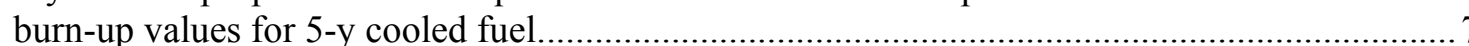

Table 2. Summary of key features of the thermal processing technologies considered in this work. All systems have been scaled to process at least $3 \mathrm{~L}$ or $36 \mathrm{~kg}$ of consolidated metal per day 


\section{ABBREVIATIONS}

\begin{tabular}{|l|l|}
\hline $\mathrm{Ga}$ & Giga-annum $\left(10^{9}\right.$ years $)$ \\
\hline $\mathrm{GHz}$ & Gigahertz $\left(10^{9} \mathrm{~s}^{-1}\right)$ \\
\hline $\mathrm{HIP}$ & Hot isostatic pressing \\
\hline $\mathrm{HUP}$ & Hot uniaxial pressing \\
\hline $\mathrm{kA}$ & Kiloamperes \\
\hline $\mathrm{kHz}$ & Kilohertz $\left(10^{3} \mathrm{~s}^{-1}\right)$ \\
\hline $\mathrm{kN}$ & Kilonewtons \\
\hline $\mathrm{kW}$ & Kilowatts \\
\hline $\mathrm{kpsi}$ & Kilo-pounds per square inch \\
\hline $\mathrm{MHz}$ & Megahertz $\left(10^{6} \mathrm{~s}^{-1}\right)$ \\
\hline $\mathrm{MTIHM}$ & Metric tons irradiated heavy metal \\
\hline MWd/t & Megawatt days per tonne (metric ton $)$ \\
\hline $\mathrm{UDS}$ & Undissolved solids \\
\hline $\mathrm{UNF}$ & Used nuclear fuel \\
\hline
\end{tabular}




\section{INTRODUCTION}

With the resurgence of nuclear power in the world, consideration is being given to the reprocessing of used nuclear fuel (UNF). As part of recycling, the management of the wastes that would be generated during processing is being discussed. In the UNF, elements with low solubility in the $\mathrm{UO}_{2}$ matrix move from the matrix to grain boundaries, pellet-pellet gaps, and fuel-cladding gaps. Of particular interest in this document are the six metals $\mathrm{Mo}, \mathrm{Pd}, \mathrm{Rh}, \mathrm{Ru}, \mathrm{Te}$, and Tc that form the "five metal phase" (Cui et al. 2004; Kleykamp et al. 1985; Kleykamp and Pejsa 1984). Tellurium was found by Cui et al (2004), but not by Kleykamp and coworkers. These metals form an alloy known as (epsilon) $\varepsilon$-metal. It forms in the grain boundaries of the $\mathrm{UO}_{2}$ matrix as $\sim 5-\mu$ m diameter particles. Because it is constituted of normally unreactive metals, these small particles largely survive the fuel dissolution process. Currently, the plan is to dispose of these particles by first dissolving them in molten Fe or stainless steel to form an ingot. Alternatively, these particles can be melted to form an ingot without first diluting with inactive (i.e. Fe) metal. As this phase contains roughly half of the Tc in UNF, it stands to reason that adding the soluble fraction of the Tc and noble metals ( $\mathrm{Pd}, \mathrm{Rh}$, and $\mathrm{Ru}$ ) into this waste form is appropriate. Therefore, the subject of this document is to investigate processes that could be used to melt or otherwise consolidate these small $\varepsilon$-metal particles and reduced Tc and noble metals into a monolith with low surface area.

After the dissolution of nuclear fuel, there remains in the dissolver a material called undissolved solids (UDS). This material consists of the $\varepsilon$-metal alloy and some $\left.\left[\mathrm{Ba}_{1-\mathrm{x}-\mathrm{y}}\left(\mathrm{Sr}_{\mathrm{x}} \mathrm{Cs}_{\mathrm{y}}\right)\right][\mathrm{U}, \mathrm{Pu}, \mathrm{RE}) \mathrm{Zr}\right] \mathrm{ZrO}{ }_{3}$, e.g. $\left.\left[\mathrm{Ba}_{0.9}(\mathrm{Sr}, \mathrm{Cs})_{0.1}\right]\left[\mathrm{U}_{0.5} \mathrm{Pu}_{0.2} \mathrm{RE}_{0.05}\right) \mathrm{Zr}_{0.25}\right] \mathrm{Zr}_{0.25} \mathrm{O}_{3}$ (Kleykamp et al. 1985). Some other undissolved material is likely to be present as well, such as molybdenum-zirconium oxides. The amount of UDS is relatively small, amounting to at most about $30 \mathrm{~kg}$ of waste per day assuming an 800 tonne UNF per year plant that is processing 5-y stored fuel with a burn-up of $50 \mathrm{GWd} / \mathrm{t}$ and averaged over $365 \mathrm{~d}$, although the actual operating efficiency would be less. Included in this $30 \mathrm{~kg}$ is the Tc and noble metals from processing liquids, assuming they are reduced to metal, recycled, and combined with the Tc and noble metals that come from the UDS. Although the actual density of the $\varepsilon$-metal phase is not well known, most of the constituent metals have densities of $12 \times 10^{3} \mathrm{~kg} / \mathrm{m}^{3}$. The density calculated from the constituent pure metal densities relative to their concentration in $\varepsilon$-metal is $12 \times 10^{3} \mathrm{~kg} / \mathrm{m}^{3}$. At this density, the maximum volume of metal produced would be about $2.5 \mathrm{~L} / \mathrm{d}$.

One of the major considerations for a waste form is its long-term durability. It is rare to find a natural analogue that has not only similar properties, but similar origin. Such is the case for the $\varepsilon$-metal. This phase or its remnants have been found as part of the natural reactors in Gabon (Gauthier-Lafaye, Holliger, and Blanc 1996). These reactors were active about $2 \mathrm{Ga}$ ago. Remnants of the $\varepsilon$-metal have been found and characterized (Utsunomiya and Ewing 2006). Results suggest that this metal phase has the durability appropriate for long-lived isotopes in a repository.

The goal of the proposed method is to consolidate the waste products into a single, low-surface area form to minimize the release rate of the long-lived ${ }^{99} \mathrm{Tc}\left(\mathrm{t}_{1 / 2}=2.13 \times 10^{5} \mathrm{y}\right)$ and ${ }^{107} \mathrm{Pd}\left(\mathrm{t}_{1 / 2}=6.5 \times 10^{6} \mathrm{y}\right)$. Temperature, pressure, and time are the key parameters for any candidate process with which to consolidate the high-surface area waste products into a monolith. Because of the relatively small volume, several technologies can be considered as viable candidates for this material. They are arc melting, induction melting, furnace melting, hot uniaxial pressing (HUP), hot isostatic pressing (HIP), sparkplasma sintering, and microwave sintering. The parameters used to compare and contrast these techniques include space needed for their operation, flexibility in accepting wide-variety of feed-stock (chemistry, form, quantity), ease of maintenance, generation of additional waste streams, cost, and any special considerations. There are some characteristics of the waste that may cause some of these technologies to be less adaptable than others. In addition to the techniques mentioned above and examined in this report, there are several consolidation techniques that have been reported in the 
literature, for example, low-temperature consolidation in a host matrix (e.g. cement, grout, etc.), shockcompaction, plasma-spray and laser melting/sintering etc. However, these techniques have been deemed impractical owing to specific limitations and practical aspects and, therefore, have not been considered in this report.

\section{Waste Composition and Quantity}

Table 1 shows the forecast composition of the waste both as UDS and as $\varepsilon$-metal phase alone. There is a small contribution to the waste from $\mathrm{Zr}$, presumably as undissolved $\mathrm{ZrO}_{2}$ from the cladding, and fission product Zr. As indicated, there is likely to be other undissolved solids, but these are as yet unknown. It is important to recognize this when selecting a process to convert these into a solid; the process should be flexible with respect to the waste composition. Figure 1 provides estimates of the cylindrical dimensions and the number of ingots needed to account for a total volume of $2.5 \mathrm{~L}$. The results shown in Figure 1 are used as a factor in selecting the size of the equipment to be used in the ranking of processes discussed below.

Table 1. Key thermal properties and the quantities of UDS and $\varepsilon$-Metal per MTIHM for two fuel burn-up values for 5-y cooled fuel.

\begin{tabular}{|c|c|c|c|c|c|}
\hline \multirow{2}{*}{ Element } & \multirow{2}{*}{$\begin{array}{l}\text { Melting } \\
\text { Point, }{ }^{\circ} \mathrm{C}\end{array}$} & \multicolumn{2}{|c|}{$100 \mathrm{GWd} / \mathrm{t}$} & \multicolumn{2}{|c|}{$25 \mathrm{GWd} / \mathrm{t}$} \\
\hline & & g/MTIHM ${ }^{1}$ & $\varepsilon$-Metal, $\mathrm{g}$ & g/MTIHM ${ }^{1}$ & $\varepsilon$-Metal, $\mathrm{g}$ \\
\hline $\mathrm{Zr}$ & 1855 & 11000 & & 2680 & \\
\hline Mo & 2623 & 10100 & 2030 & 2530 & 507 \\
\hline Tc & 2204 & 2030 & 1010 & 620 & 310 \\
\hline $\mathrm{Ru}$ & 2337 & 7070 & 3110 & 1700 & 746 \\
\hline $\mathrm{Rh}$ & 1963 & 910 & 350 & 410 & 160 \\
\hline $\mathrm{Pd}$ & 1552 & 4560 & 4510 & 1050 & 1030 \\
\hline Sum & & 35700 & 11000 & 8970 & 2750 \\
\hline $\begin{array}{c}\text { Throughput, } \\
\text { MTIHM/y }\end{array}$ & & 800 & & 800 & \\
\hline UDS, kg/y & & & $11.6^{2}$ & & $2.9^{2}$ \\
\hline $\begin{array}{l}\text { Required } \\
\text { throughput, } \\
\mathrm{kg} / \mathrm{d}\end{array}$ & & $24.7^{3}$ & & $6.3^{3}$ & \\
\hline $\begin{array}{l}\text { Production } \\
\text { efficiency }\end{array}$ & & & 0. & & \\
\hline
\end{tabular}

1) These are the totals contained in the UNF; of the $\mathrm{Zr}, 5 \%$ is part of the UDS and is combined with the $\varepsilon$-metal.

2) Contains the $5 \%$ of the total $\mathrm{Zr}$ as part of the UDS.

3) Total UDS plus recycled noble metals.

\section{Parameters Affecting Consolidation}

The act of consolidation requires temperature, pressure, and time. Each of these parameters is dependent on the thermo-chemical-physical properties of the constituents or phases that may form during the consolidation process. A fairly detailed knowledge of the thermodynamics (Kaye, Lewis, and Thompson 
2007; Kleykamp 1989) is known but the kinetics of phase formation in this multielement system comprising $\mathrm{Mo}, \mathrm{Pd}, \mathrm{Rh}, \mathrm{Ru}$, $\mathrm{Tc}$, and $\mathrm{O}$ is not known at present ${ }^{\mathrm{a}}$. Further, the compositions of the incoming waste stream also vary over the course of multi-year operation of the plant, as the composition of the $\varepsilon$-metal is known to change with fuel burnup (Kleykamp et al. 1985). Recycle of the soluble fractions of the noble metal and Tc also complicates the prediction of the composition of the end product.

(A) Melting and Casting: The waste material is heated until molten, cast into an ingot, and allowed to cool. Process variations are possible depending on the heat source.

a. Advantage: The method ensures mixing of the raw materials, formation of $\varepsilon$ metal and eventual solidification into a monolith with minimal porosity.

b. Disadvantage: Concerns relating to (i) generating and maintaining high temperatures $\left(>2000{ }^{\circ} \mathrm{C}\right.$ ) (ii) volatilization and capture of metal fumes, iii) potential for segregation of phases such as oxides, and (iv) containing the reactive melt.

(B) Sintering: Agglomeration and consolidation occurs through solid-state diffusion under a pressure or load. Process variations are possible depending upon the source of heat and/or the means by which pressure/load is applied.

a. Advantage: Global melting is not involved, thus, minimizing concerns relating to melting as listed in (A) b, above.

b. Disadvantage: The process requires pressure or load to help sinter the raw material to full or close-to-full density, thus, necessitating a load or pressure generation system whose operation in a radioactive hot-cell can create safety and maintenance concerns.

It is noted that, depending on the local composition and temperature, a technique belonging to one type may involve some aspects of the other. For example, a sintering process may involve formation of transient liquid phases and a melting process may involve non-molten phases.

It should also be noted that the systems discussed below are sized to accommodate at least 3-L/d throughput for the consolidated metal.

\footnotetext{
${ }^{a}$ Tellurium is also part of the $\varepsilon$-metal, but is ignored in these studies, for the moment (see the Introduction).
} 


\section{Arc Melting}

In this method, a high frequency arc (plasma) is used to melt the target material. There are basically two methods by which this can be done. A pressed pellet of the metal to be melted is placed on a water-cooled hearth and the arc is struck between a tungsten rod and a grounded metal spike. The arc is then moved to the pellet by moving the tungsten wand, usually by hand. Temperatures in excess of $3000{ }^{\circ} \mathrm{C}$ may be achieved, depending on the power input. The wand is moved back and forth to achieve good stirring of the molten mass and uniform melting throughout the charge, both achieved by the turbulence induced by the plasma arc. In the second method, a crucible containing an initial charge of $\varepsilon$-metal is where the melting takes place. Additional metal is added after the initial charge is molten. A gas atmosphere is required to carry the arc. Typically, an inert gas, such as $\mathrm{He}$, Ar, or $3 \mathrm{vol} \% \mathrm{H}_{2}$ in $\mathrm{Ar}$, is used either static or flowing. Low oxygenbearing gases are used to avoid slag formation.

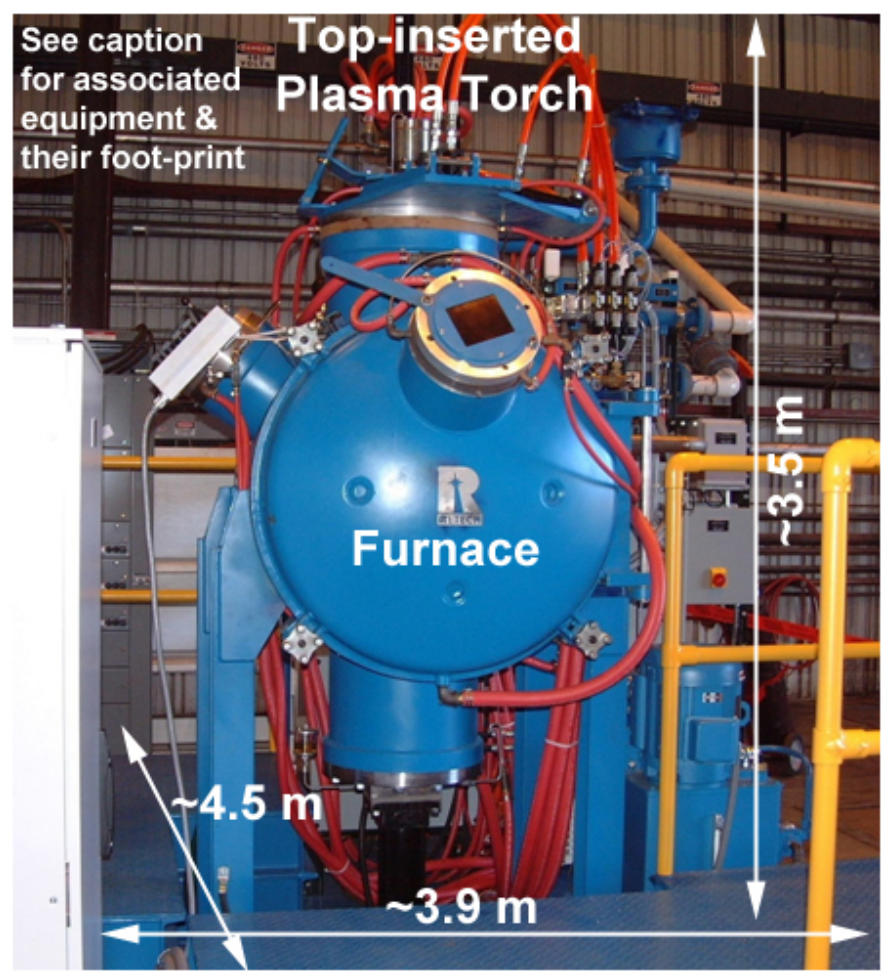

Figure 2. Single-torch plasma arc furnace by Retech Systems, LLC (Ukiah, CA).

A picture of the typical industrial arc melter is shown in Figure 2. In this example system, a single, nonconsumable plasma torch (transferred-arc type) is inserted from the top and can be manipulated along $\mathrm{x}, \mathrm{y}$ and $\mathrm{z}$ axes. The raw material is inserted in compact form (size of a hockey-puck) and arc melted in a water-cooled copper hearth (diameter $\geq 100 \mathrm{~mm}$, length is selectable) in helium gas atmosphere. The ingot is withdrawn within the chamber during continuous feeding and melting until the desired length of the ingot has been formed. Subsequently, the torch is shut-down, ingot allowed to cool and chamber vented to remove the finished ingot. Associated equipment (not visible in the above image) has a total footprint of $\sim 4.75 \mathrm{~m} 2$ and is itemized as follows: Power supply $(\sim 0.9 \mathrm{~m} \times \sim 1.5 \mathrm{~m})$, motor control center $(\sim 0.4 \mathrm{~m} \times \sim 0.5 \mathrm{~m})$, water system $(\sim 1.2 \mathrm{~m} \times \sim 1.8 \mathrm{~m})$, control console $(\sim 0.8 \mathrm{~m} \times \sim 0.8 \mathrm{~m})$ and vacuum pump $(\sim 0.5 \mathrm{~m} \times \sim 0.8 \mathrm{~m})$.

Advantages: This method is very fast. The arc melting process takes place in seconds to minutes. The metal is cooled rapidly because the melting is done on a water-cooled hearth. This also prevents the melt from sticking to the hearth.

Disadvantages: Because this method requires gas to be present albeit inert gas, some contamination is likely. However, the main disadvantage is the likelihood of high volatility of one or more of the metals or oxides, although laboratory studies with 10 -g specimens indicate that less than 1 mass $\%$ of the metal is volatilized. Metal volatility generates problems for cleanup (the inside of the arc melter) to minimize radiation to the workers and off-gas cleanup (secondary waste or recycle). Accumulation of slag, especially from the non-metallic portion of the UDS, is likely to cause problems with arc melting, requiring higher power input to achieve a suitable melt. The slag may need to be disposed as secondary waste, but could be incorporated into the metal waste form, albeit not homogeneously dissolved. 
Size: Although laboratory arc melters are commonly available and may occupy only a few square meters of space, they are limited to producing "thumb-nail" sized castings that are insufficient for the volume of waste $(2.5 \mathrm{~L} /$ day $)$ anticipated in this work. An "industrial-sized" arc melter may occupy a radioactive space of $\sim 18 \mathrm{~m}^{2}$ with an additional $\sim 5 \mathrm{~m}^{2}$ required in non-radioactive space for controls and cooling water. This size can potentially be scaled down to match the daily waste requirements of $2.5 \mathrm{~L}$. In the typical application, the feed to an arc melter is in the form of coarse granules to small pellets. It is unclear if a powder, like the UDS and $\varepsilon$-metal from the dissolution of fuel, can be fed to the arc melter without substantial losses caused by the turbulence in the plasma. Tests at a vendor are needed to quantify the viability of a powder feed. If coarser powders are needed, additional hot cell space is needed to accommodate a press to make "green" compacts from the incoming powder feed-stock. We estimate that $\sim 1 \mathrm{~m}^{2}$ is needed for a bench-top system.

\section{Induction Melting}

In this method, a crucible is heated either through a susceptor or directly with a radio frequency induction coil (Figure 3). In the case of a metal that is to be heated, the metal itself absorbs the radio frequency energy and is, therefore, heated. The unit can be flushed with inert gas or run under vacuum. In the case of flowing gas, the system can be configured to run continuously and the liquid poured into a canister.

The example system in Figure 3 is rated to $150 \mathrm{~kW}$ with an output frequency between 15 $45 \mathrm{kHz}$. The work head can be located up to $30 \mathrm{~m}$ away from the power control module. Copper coils of different inner working diameters, to accommodate different sized crucibles/work piece, can be affixed to the work head.

Advantages: These units are easy to operate. The metal is heated quite rapidly, 1 to 10 minutes. The cycle time is short allowing for multiple runs to be made during the day, hence a smaller melter.

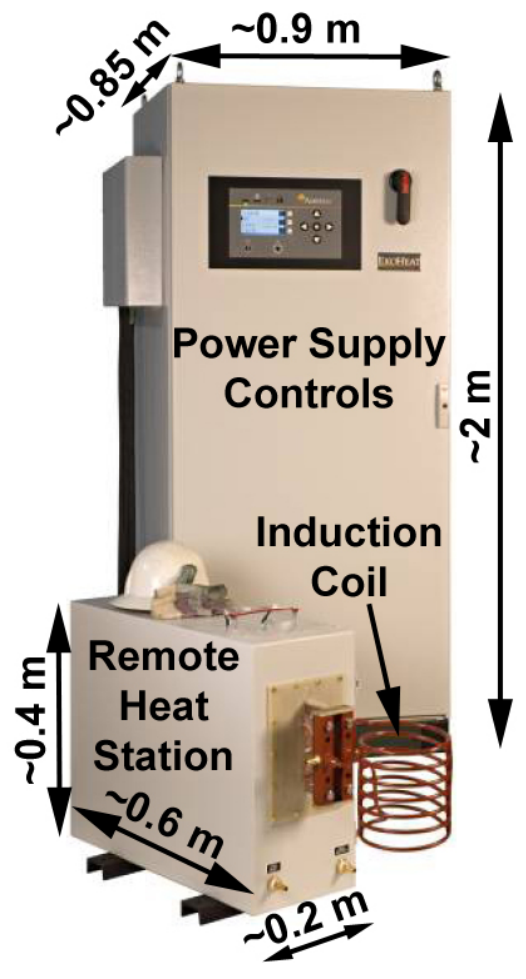

Figure 3. Induction heating system, model Ekoheat by Ameritherm, Inc (Ambrell/Ameritherm Inc. 2010).

Disadvantages: As with the arc melter, volatility is the major disadvantage. Slag accumulation also represents a disadvantage, because the slag has a lower density and accumulates on the surface of the molten metal. It is another waste form that would require characterization and performance determination. Current experimental evidence suggests that exotic crucible materials may be needed to contain the molten metal. This results in an added complexity to this process.

Size: The equipment for this technique is very compact and requires the least amount of space of all the techniques evaluated: $1-2 \mathrm{~m}^{2}$ of radioactive and non-radioactive space each. The cooling water supply may add another $1 \mathrm{~m}^{2}$ of non-radioactive space for a total space requirement of $3-5 \mathrm{~m}^{2}$. 


\section{Furnace Melting}

This method could be set up as a continuous or batch operation (Figure 4). Because of the high temperatures involved and the reactivity of the constituent metals to $\mathrm{O}_{2}$ in air, these operations would have to take place in an inert atmosphere, indicating that a batch operation is more likely. Since the molten metal is reactive with typical crucible materials, such as alumina or graphite, a graphite crucible with a coating of $\mathrm{CeO}_{2}$ or $\mathrm{ZrO}_{2}$ would have to be used. The metal powders would be added either continuously or in batch to the crucible. In continuous operation, the overflow from the crucible would flow into a cold canister that would be located in an airlock. After filling

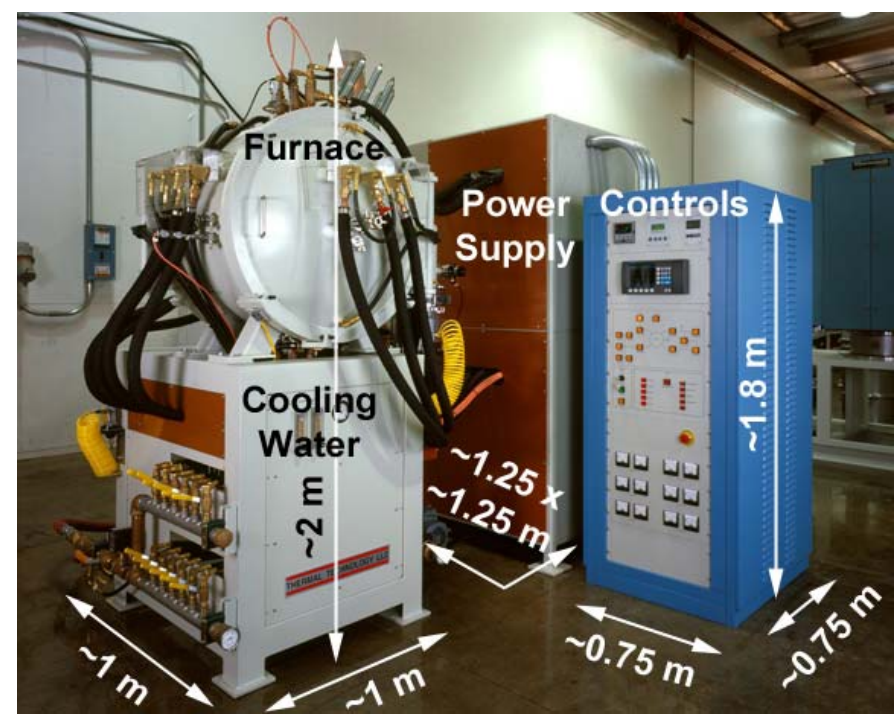

Figure 4. A front loaded high-temperature furnace (Model 121212 by Thermal Technology (Thermal Technology LLC 2010b)) the canister would be removed, sealed, and decontaminated. In batch mode, metal powder would be added to a crucible that, once filled, would be loaded into a canister and a new one put in its place. An alternate batch operation would be to place crucibles filled with metal powder on a conveyor through a tunnel furnace with the correct temperature profile and inert gas atmosphere. These high temperature furnaces are commonly used in the preparation of nuclear fuel pellets and operate at about $1500^{\circ} \mathrm{C}$ with a $\mathrm{H}_{2}$ atmosphere in a glove box.

The example shown in Figure 4 has a working zone of $30 \mathrm{~cm}$ x $30 \mathrm{~cm}$ x $30 \mathrm{~cm}$ and a choice of heating elements: tungsten $\left(\mathrm{T}_{\max } \sim 2500{ }^{\circ} \mathrm{C}\right)$, tantalum $\left(\mathrm{T}_{\max } \sim 2500{ }^{\circ} \mathrm{C}\right)$ or graphite $\left(\mathrm{T}_{\max } \sim 2500{ }^{\circ} \mathrm{C}\right)$. Other equipment variations include choice of atmosphere (vacuum, inert, reducing), loading access (top, bottom, front, bell jar) and working zone size. For example, a single $2.5 \mathrm{~L}$ cylindrical sample (Figure 1) could be fabricated using models with work zones ranging from $\sim 254 \mathrm{~mm}$ dia. $\times \sim 356 \mathrm{~mm}$ height to $\sim 1220 \mathrm{~mm}$ dia. $\times \sim 1830 \mathrm{~mm}$ height. Alternately, the $2.5 \mathrm{~L}$ total material volume could be incorporated into 2 cylindrical samples using a smaller model with work zone ranging from 127-150 mm dia. $\times 254$ $305 \mathrm{~mm}$ height. The furnace can be located remote from the rest of the system.

Advantages: Since there is a large body of experience with these types of furnaces, safe and efficient operations can be assured. Near continuous operation can be achieved. The sizing of the furnace would be scaled to meet the low demand of this operation.

Disadvantages: Coated crucible lifetime could be a problem especially if they are single use. Single use would mean that there would be either a significant secondary waste volume or decrease in the metal storage density ${ }^{\mathrm{b}}$ because of the volume occupied by the crucibles in which the metal would be contained.

\footnotetext{
${ }^{\mathrm{b}}$ Storage density is defined as the actual volume occupied by a kilogram of waste in storage. The volume includes that occupied by the canister and other associated storage media.
} 
If a $\mathrm{H}_{2}$ atmosphere is needed, implementation of extra safety measures and off-gas handling would be needed. While the footprint of a single batch furnace would be smaller than a tunnel furnace, the operation of the furnace would be complicated by the use of high temperatures in a confined space and the batch operation.

Size: As mentioned above, the footprint can vary quite a bit depending on the furnace type. For the example considered here. The space required could be on the order of $\sim 3 \mathrm{~m}^{2}$

\section{Hot Uniaxial Pressing}

In this technique, the metal powders are loaded into a die, usually graphite (perhaps coated) or alumina, with a moveable punch inserted from below and an opposing punch inserted from above. The die and punch assembly is heated to some temperature and pressure applied to consolidate the powders. Again, because the metals react with oxygen, the operation would have to be carried out in an inert atmosphere or under vacuum. The temperature used in this method would not be high enough to cause the metal or any alloy to melt, but sufficiently high to allow sintering of the metal to near theoretical density. One physical phenomenon that needs to be addressed is the volume changes that might occur as a various crystal phases form during the cooling of the metal. Slight expansions can cause the die body to be destroyed. However, this would be determined before a process is installed in an operating plant.

With a HUP (Figure 5) there is a choice of heating elements (graphite $\left(\mathrm{T}_{\max } \sim 2250^{\circ} \mathrm{C}\right.$ ), tungsten $\left(\mathrm{T}_{\max } \sim 2500^{\circ} \mathrm{C}\right.$ ) or molybdenum $\left(\mathrm{T}_{\max } \sim 1700{ }^{\circ} \mathrm{C}\right)$ ) and atmosphere (vacuum or inert gas atmospheres). As an example, a single 2.5 L cylindrical sample (Figure 1) could be fabricated by model HP55 (die size $\sim 203 \mathrm{~mm}$ dia. $\times \sim 305 \mathrm{~mm}$ height $(8 " \times 12$ "), 30 tons press capacity), HP 100 (die size $\sim 152$ $\mathrm{mm}$ dia. $\times \sim 305 \mathrm{~mm}$ height $(6 " \times 12$ "), 50 tons press capacity), or other larger sized-load capacity models. Alternately, the $2.5 \mathrm{~L}$ total material volume could be incorporated into 2 cylindrical samples using a smaller press, HP50 (die size $\sim 152 \mathrm{~mm}$ dia. $\times \sim 152 \mathrm{~mm}$ height ( 6 " $\times 6$ "), 25 tons press capacity). The furnace can be located remote from the rest of

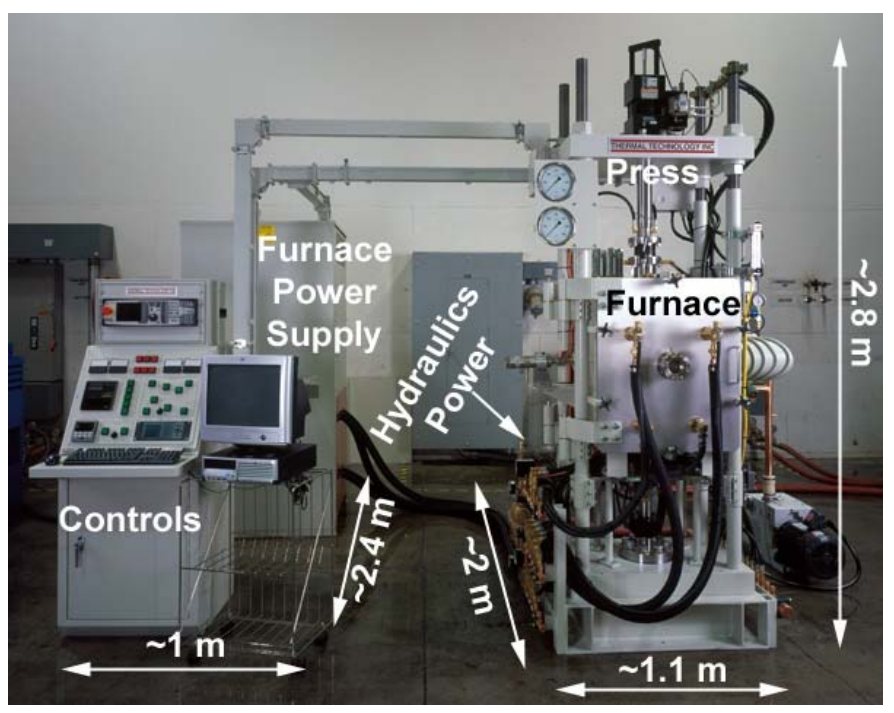

Figure 5. Hot uniaxial press (Model Hot Press-25 tons by Thermal Technology (Thermal Technology LLC 2010a)). the system

Advantages: This process would be an inherently lower temperature process than those discussed above. Volatility of the metal with the highest vapor pressure would be essentially eliminated, since the temperatures are low and the system is 'semi-sealed' during the consolidation step. The metal billet that comes from this process is likely to be at or very close to the same density as from a melt process.

Disadvantages: Unless the die can be loaded while it is hot, this process is inherently slow. Thus, the die and punch set needs to be cooled after the consolidation has been achieved. Although large die and punch sets are available, it is uncertain if large enough ones ( $\sim 3 \mathrm{~L}$ maximum for $100 \mathrm{MWd} / \mathrm{t}$ fuel case; $0.5 \mathrm{~L}$ for $25 \mathrm{MWd} / \mathrm{t}$ [Table 1]) are available to match the daily throughput requirements with a one cycle per day 
process. Additionally, these presses occupy a lot of space; the larger the die and punch set, the larger the occupied space.

Size: The footprint is likely to be on the order of 4 to $8 \mathrm{~m}^{2}$ and the height up to $3 \mathrm{~m}$.

\section{Hot Isostatic Pressing}

Hot isostatic pressing is a variant of hot uniaxial pressing - consolidation under isostatic pressure and temperature. In this case, the metal powder is loaded into a metal can, perhaps coated with a $\mathrm{CeO}_{2}$ or $\mathrm{ZrO}_{2}$. The can is evacuated and placed in a pressure vessel that contains heating elements. The temperature of the can is raised on some predetermined schedule while pressure is applied through gas pressure inside of the heated pressure vessel. Since the gas pressure is uniform (isostatic), the can consolidates in all directions. The cans are designed in such a way as to facilitate the consolidation and yield a product with uniform dimensions that is easily handled. The temperatures that are needed are insufficient to cause any melting in the product can. Volume changes from phase changes on cooling should not affect the integrity of the main containment.

A picture of a typical hot isostatic press is shown in Figure 6. This unit features graphite furnace $\left(\mathrm{T}_{\max }\right.$ $\left.\sim 2000{ }^{\circ} \mathrm{C} / 3632{ }^{\circ} \mathrm{F}\right)$ and a maximum operating pressure of $207 \mathrm{MPa}(30 \mathrm{kpsi})$. As an example, a single $2.5 \mathrm{~L}$ cylindrical sample (Figure 1) could be fabricated in its work zone that measures inner diameter of $\sim 203 \mathrm{~mm} \times \sim 305 \mathrm{~mm}$ height $(8 " \times 12 ")$. Not shown in the image is a computer system that is used to controls the system

Advantages: This process would inherently be a lower temperature process than arc, induction, or furnace melting. Volatility of the high vapor pressure metals would be eliminated because of the lower temperature and the sealed can. Hot isostatic pressing in radioactive waste management has been avoided for many years. However, it continues to be promoted by the scientists at the Australian Nuclear Science and Technology Organization and is now the baseline process for one of the wastes at the Idaho National Laboratory site (Zhang et al. 2008) and the high-level waste byproducts of medical molybdenum production in Australia (ANSTO 2011).
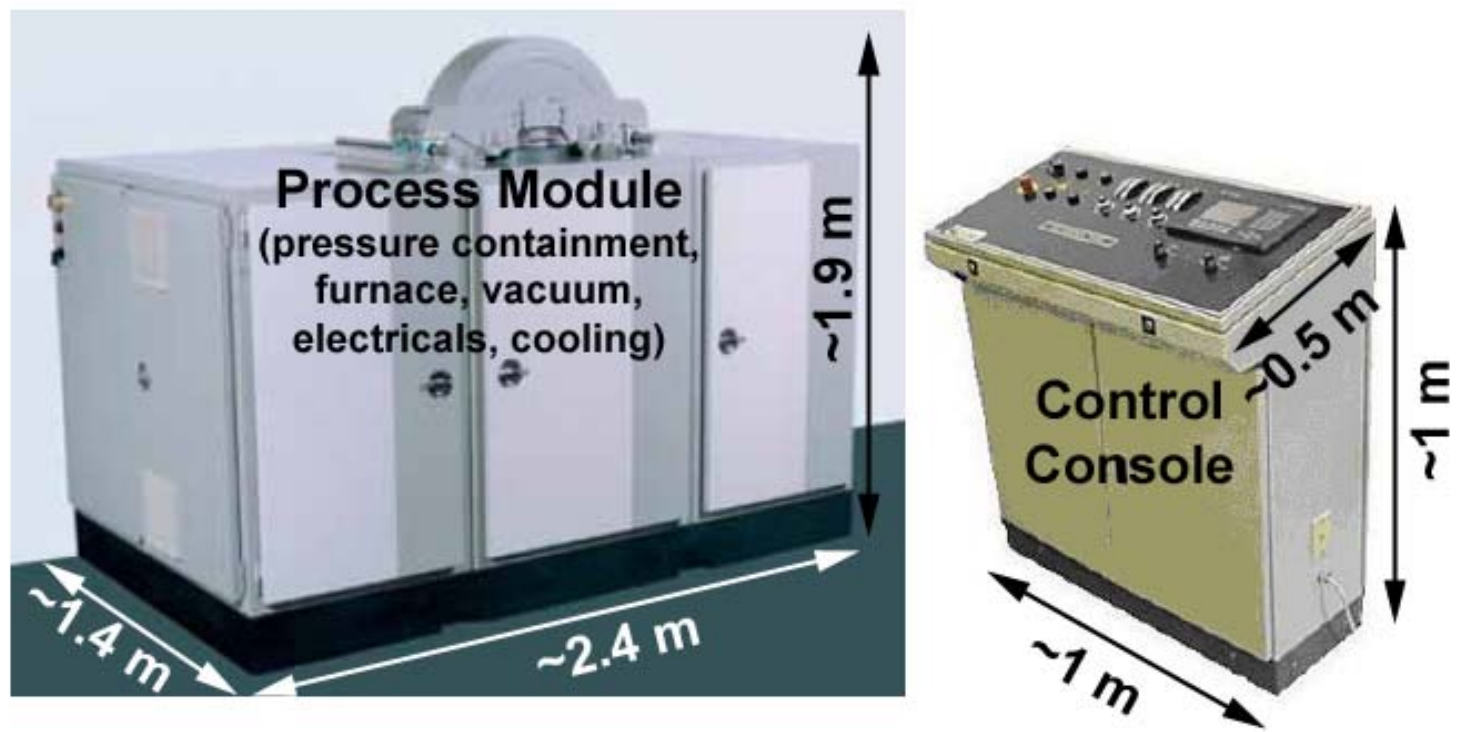

Figure 6. Hot isostatic press (HIP) system (Model Mini-HIPper QIH-15e, by Avure Technologies (Avure Technologies 2010)). 
Disadvantages: This apparatus occupies a large space for the pressure vessel, controls, and gas handling and storage. Because it is a high pressure device, the safety requirements are likely to increase the footprint over that in a typical non-nuclear installation. The containment cans need to be carefully designed. A very reliable apparatus to seal the cans is needed to avoid a leak and possible subsequent contamination of the pressure vessel.

Size: A typical unit in which about $2.5 \mathrm{~L}$ of metal could be processed at once is about $1 \mathrm{~m} \times 0.5 \mathrm{~m}$ for the control unit plus about $1.4 \mathrm{~m} \times 2.4 \mathrm{~m}$ for the pressure vessel and associated equipment.

\section{Spark Plasma Sintering}

Spark plasma sintering is a type of fieldassisted sintering technique (Groza 2006) in which the sintering process is activated by the passage of high-amperage current/current pulse(s) through the powder while externally applied mechanical load is used to densify the powder (Figure 7). Electrical discharges between the powder particles is believed to "clean" the particle surfaces of impurities, thus, enabling intergranular cohesion and enhancing neck formation. The passage of electric currents heats the powder particles with points of contact between powder particles (necks) heating preferentially. Thus, electric currents enhance plasticity and diffusion of matter to the necks leading to high densification rates. The powder is loaded into graphite die and the graphite loading rams themselves serve as the current conductors for the passage of current through the sample. For electrically conductive or insulating powders, the current may flow through either the powders or dies. With further increase in temperature, the conductivity of the powders can change, which, in turn, can influence the preferential path of the electric current and the resulting Joule heating. Process variables include current and pulse durations, external mechanical load, hold time and the sequence

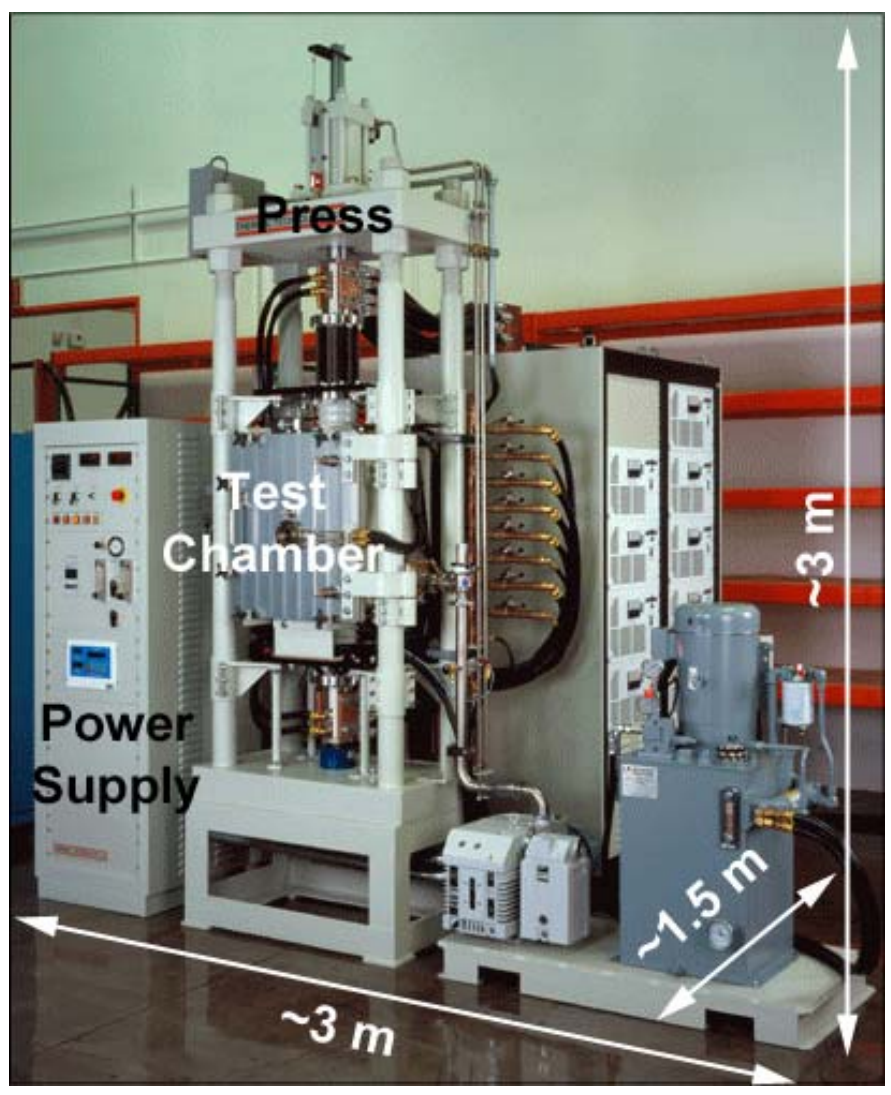

Figure 7. Spark plasma sintering system (Model SPS25-10 by Thermal Technology LLC (Thermal Technology LLC 2010b)). of application of current and load.

Figure 7 shows and example that features a maximum operating temperature of $2200^{\circ} \mathrm{C}$ and can be used in vacuum, argon, nitrogen or helium atmosphere. It has a pressing capability of $\sim 222 \mathrm{kN}$ (25 ton) total force and a $10 \mathrm{kA}, 10 \mathrm{VDC}$ pulsed power supply with manually adjustable and programmable squarewave form with current or voltage mode operation. The test chamber inside dimensions are $432 \mathrm{~mm}$ (17") wide $\times 432 \mathrm{~mm}$ (17") deep $\times 508 \mathrm{~mm}(20$ ") high. Graphite punch and dies can be machined depending upon the size of the sample to be fabricated. Equipment can be custom-built with capability up to $\sim 2220 \mathrm{kN}$ (250 tons) of force and up to $60 \mathrm{kA}$ current supply. 
Advantages: This process may enable good intergranular strength between different phases and hence, be robust enough to handle different types of incoming materials. Of the various sintering processes examined in this report, this process is expected to require the lowest processing temperature and time due to enhanced sintering kinetics. Faster processing and lower processing temperatures will possibly result in reduced wear and tear of the equipment leading to longer continuous operation without the need for equipment repairs. Absence of global melting may also reduce any volatile radioactive species, although they would be contained within the die assembly.

Disadvantages: Similar to other sintering processes considered here, the process parameters for the spark plasma sintering process need to be determined. The effect of phase-change associated expansion of powdered compacts during sintering will also need to be considered to avoid failure of the dies.

Size: A typical equipment and associated power supply, cooling water system etc. would occupy around 5 $\mathrm{m}^{2}$ of space and a height of $\sim 3 \mathrm{~m}$. Less than half of the floor space would be needed by the hot press (located in the radioactive space) while the remainder equipment can be located remotely.

\section{Microwave Sintering}

Microwave or microwave assisted sintering is a technique where the microwave heating alone or in conjunction with conventional furnace heating, is used to sinter granular material. Typical furnaces (Figure 8) operate at $915 \mathrm{MHz}$ or $2.45 \mathrm{GHz}$ and have been used to sinter metals and oxide ceramics.

Microwave sintering can produce fully dense parts and with small grain-size.

The microwave furnace in Figure 8 includes a $2.45 \mathrm{GHz}$ generator operates with a variable output power ranging from $0.6-6 \mathrm{~kW}$. The microwave furnace chamber is $203 \mathrm{~mm}$ (8") diameter $\times 203 \mathrm{~mm}(8$ ") height with a maximum operating temperature of $1600^{\circ} \mathrm{C}$ and a controlled atmosphere such as $\mathrm{N}_{2}, \mathrm{Ar}$, $\mathrm{N}_{2}+\mathrm{H}_{2}, \mathrm{Ar}+\mathrm{H}_{2}$ and $\mathrm{CO}_{2}$.

Advantages: Microwave heating offers the advantage of heating the (powder) sample volumetrically whereas conventional radiant furnaces heat the outside of the sample while the inner areas heat more slowly through conduction. Therefore, rapid and uniform

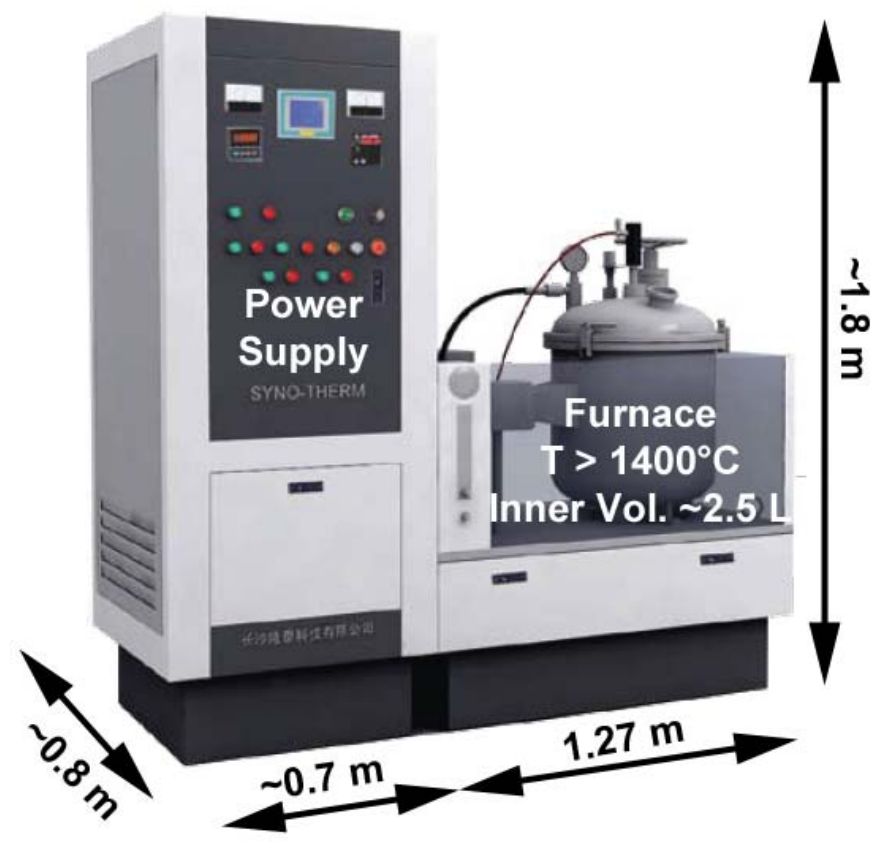

Figure 8. Microwave high-temperature furnace system, (Model HAMiLab-V6 by Spheric Technologies, Inc. (Spheric Technologies Inc. 2010)). heating can produce fully-dense parts in an energy efficient manner. Since the sintering process does not require melting, volatile radioactive species should be minimized.

Disadvantages: The limitations of the maximum temperature available in the commercial systems $\left(\sim 1500-1700{ }^{\circ} \mathrm{C}\right)$ and lack of knowledge on the microwave coupling with waste materials are the two main disadvantages. It is likely that a temperature of $1700{ }^{\circ} \mathrm{C}$ may be insufficient to sinter the hightemperature melting elements (such as Mo) as well as various oxides and other phases present in the 
waste. Further, the efficiency of microwaves to couple with the waste materials is also unknown and needs to be determined.

Size: The entire system is quite compact and occupies $<2 \mathrm{~m}^{2}$ floor space with $\sim 2 \mathrm{~m}$ height. The microwave chamber, where sintering of the waste occurs, can be located in the hot space and would occupy $\sim 1 \mathrm{~m}^{2}$ of space while the controls can be located remotely.

\section{Preferred Technology}

Criteria used to evaluate the various technologies listed include: Flexibility in accepting wide-variety of feed-stock (chemistry, form, quantity), ease of long-term maintenance, space needed for their operation, generation of additional waste streams, cost, and any special considerations. Broadly speaking, sintering techniques have been ranked above the melting techniques (except hot uniaxial pressing) since consolidation can be accomplished at temperatures lower than the melting point, which simplifies the process operation, minimizes volatiles, and reduces maintenance.

Microwave sintering technique ranks highest because of the simplicity of the heating source (microwaves) and operation and very compact foot-print. However, since the maximum operation temperature $\left(1700^{\circ} \mathrm{C}\right)$ may be low relative to the temperature required to melt the metals involved. This method needs to be further investigated to validate it as the primary technique for processing the metal waste stream.

Spark plasma sintering is ranked second; it overcomes the potential drawback of "low" global operating temperature of microwave sintering because temperatures that exceed the melting point locally are generated at particle interfaces. Therefore, it has the distinct advantage that the volatility of metals is essentially eliminated while providing a nearly theoretically dense material. Little or no secondary waste is envisioned from this process, although there will occasionally be a spent die assembly. The equipment also has a small foot print and some development work is needed to better determine the viability of this technique.

Hot isostatic pressing is ranked third. It is a very mature technique is expected to produce fully dense materials. Owing to the use of pressurized equipment (100s of MPa), there is a potential, albeit low, danger of pressure vessel rupture and hence, this technique is ranked below the other sintering techniques. This technique may lend itself to treating multiple waste streams with the same basic process equipment because there is low chance of cross contamination due to the sealed containers being HIPed.

Induction melting is ranked fourth. It is ranked lower than the sintering techniques because melting can lead to volatility. It is ranked highest of the melting techniques because of the simplicity of equipment and operation. Problems associated with a cooled crucible and insulating it from the induction coils need to be worked out.

Another advantage of these first three methods is that there is less likelihood that a separate slag phase, from the oxide portion of the UDS, is generated. The non-metallic UDS is likely to be isolated in the metal as small granules.

Arc melting is ranked fifth. Although the apparatus is readily adapted for use in a hot cell and the process is fast and flexible, the large footprint of the apparatus (among the largest of the techniques examined) is the main reason for its low ranking. Although high throughput is not need, the speed with which the metal can be heated and cooled should minimize the volatile losses. The process can be made semicontinuous resulting in a single $2.5 \mathrm{~L}$ or two $1.25 \mathrm{~L}$ cans per day, depending on the burn-up of the fuel being processed. 
Furnace melting is ranked sixth and hot uniaxial pressing ranked seventh because of complexity of operation of high-temperature furnaces and loading equipment (for the latter). There are potentially many problems with such equipment (water leaks, seals replacement, heating element burn-out etc.) even under normal conditions that would be further exacerbated and would be a challenge to fix when operating in a radioactive environment.

These preliminary rankings are not based on an extensive engineering evaluation and should only be used in guiding further research. Further evaluations need to be done at vendor sites to gather information that can be used in a more in-depth analysis. For example, arc melting is ranked low, in part because we think that pretreatment of the UDS and $\varepsilon$-metal powder may be needed. However, there may be process controls that allow fine powders to be fed to the melt without the forecasted difficulties in getting the powder into the melt. This might be something as simple as keeping the plasma and the powder handling in separate areas of the molten ingot. Upon further evaluation, the rankings discussed here could change. 
Table 2. Summary of key features of the thermal processing technologies considered in this work. All systems have been scaled to process at least $3 \mathrm{~L}$ or $36 \mathrm{~kg}$ of consolidated metal per day.

\begin{tabular}{|c|c|c|c|c|c|c|c|c|c|c|}
\hline \multirow[b]{2}{*}{ Technique } & \multicolumn{3}{|c|}{$\begin{array}{c}\text { Radioactive Space } \\
\text { Requirements* }\end{array}$} & \multicolumn{3}{|c|}{$\begin{array}{c}\text { Non-radioactive Space } \\
\text { Requirements* }\end{array}$} & \multirow{2}{*}{$\begin{array}{c}\text { Maximum } \\
\text { Temperature } \\
{ }^{\circ} \mathrm{C}\end{array}$} & \multirow{2}{*}{$\begin{array}{c}\text { Approximate } \\
\text { Equipment Cost } \\
\$ \mathrm{~K}\end{array}$} & \multirow{2}{*}{$\begin{array}{l}\text { Approximate } \\
\text { Maintenance } \\
\text { Schedule }\end{array}$} & \multirow[b]{2}{*}{ Rank } \\
\hline & $\begin{array}{l}\text { Floor } \\
\text { Space } \\
\mathrm{m}^{2} \\
\end{array}$ & $\begin{array}{c}\text { Vertical } \\
\text { Space } \\
\mathrm{m}\end{array}$ & $\begin{array}{l}\text { Volume } \\
\mathrm{m}^{3}\end{array}$ & $\begin{array}{l}\text { Floor } \\
\text { Space } \\
\mathrm{m}^{2} \\
\end{array}$ & $\begin{array}{c}\text { Vertical } \\
\text { Space } \\
\mathrm{m}\end{array}$ & $\begin{array}{l}\text { Volume } \\
\mathrm{m}^{3}\end{array}$ & & & & \\
\hline $\begin{array}{l}\text { Microwave } \\
\text { Sintering }\end{array}$ & 1 & 1 & 1 & 1 & 2 & 1 & 1600 & 125 & Monthly-Annual & 1 \\
\hline $\begin{array}{c}\text { Spark } \\
\text { Plasma } \\
\text { Sintering } \\
\end{array}$ & 2 & 3 & 5 & 3 & 3 & 7 & 2400 & 420 & Bi-annual-Annual & 2 \\
\hline $\begin{array}{c}\text { Hot } \\
\text { Isostatic } \\
\text { Pressing } \\
\end{array}$ & 3 & 2 & 7 & 1 & 1 & 1 & 2000 & 520 & Bi-annual-Annual & 3 \\
\hline $\begin{array}{l}\text { Induction } \\
\text { Melting }\end{array}$ & 1 & 1 & 1 & 1 & 2 & 2 & $2500-3000$ & 75 & Bi-annual-Annual & 4 \\
\hline $\begin{array}{c}\text { Arc } \\
\text { Melting } \\
\end{array}$ & 18 & 4 & 62 & 5 & 2.5 & 12 & $>3000$ & 755 & Monthly-Quarterly & 5 \\
\hline $\begin{array}{l}\text { Furnace } \\
\text { Melting }\end{array}$ & 1 & 2 & 2 & 2 & 2 & 4 & 2500 & 250 & Bi-annual-Annual & 6 \\
\hline $\begin{array}{c}\text { Hot } \\
\text { Uniaxial } \\
\text { Pressing }\end{array}$ & 2 & 3 & 6 & 2 & 3 & 7 & 2500 & 275 & Bi-annual-Annual & 7 \\
\hline
\end{tabular}

* The values are estimates. The actual system may be smaller or require additional clearances around the equipment. Round-off errors should be anticipated in the volume calculations. 


\section{References}

Ambrell/Ameritherm Inc. 2010, "Ekoheat Induction Heating Systems." Vol 2010.

ANSTO. 2011, Management of Radioactive Waste in Australia. Technical, Australian Nuclear Science and Technology Organisation, Lucas Heights, NSW Australia.

Avure Technologies. 2010, "Hot Isostatic Press (HIP) Systems." Vol 2010.

Cui, D, J Low, CJ Sjostedt, and K Spahiu. 2004, "On Mo-Ru-Tc-Pd-Rh-Te Alloy Particles Extracted from Spent Fuel and Their Leaching Behavior under Ar and H-2 Atmospheres." Radiochimica Acta 92:551-55.

Gauthier-Lafaye, F, P Holliger, and PL Blanc. 1996, "Natural Fission Reactors in the Franceville Basin, Gabon: A Review of the Conditions and Results of a "Critical Event" in a Geologic System." Geochimica et Cosmochimica Acta 60:4831-52.

Groza, JR. 2006, "Field-Activated Sintering." in Asm Handbook - Powder Metal Technologies and Applications, Vol 7, pp. 583-89. ASM International, Materials Park, Ohio.

Kaye, MH, BJ Lewis, and WT Thompson. 2007, "Thermodynamic Treatment of Noble Metal Fission Products in Nuclear Fuel." Journal of Nuclear Materials 366:8-27.

Kleykamp, H. 1989, "Constitution and Thermodynamics of the Mo-Ru, Mo-Pd, Ru-Pd, and Mo-Ru-Pd Systems." Journal of Nuclear Materials 167:49-63.

Kleykamp, H, JO Paschoal, R Pejsa, and F Thummler. 1985, "Composition and Structure of FissionProduct Precipitates in Irradiated Oxide Fuels - Correlation with Phase Studies in the Mo-Ru-Rh-Pd and Bao- $-\mathrm{UO}_{2}-\mathrm{ZrO}_{2}-\mathrm{MoO}_{2}$ Systems." Journal of Nuclear Materials 130:426-33.

Kleykamp, H and R Pejsa. 1984, "X-Ray Diffraction Studies on Irradiated Nuclear-Fuels." Journal of Nuclear Materials 124:56-63.

Meyers, MA. 1994. Dynamic Behavior of Materials. John WIley \& Sons, Inc., New York.

Rana, MA. 2008, "Challenges in Spent Nuclear Fuel Final Disposal: Conceptual Design Models." Nuclear Science and Techniques 19:117-20.

Spheric Technologies Inc. 2010, "Microwave High-Temperature Furnace System." Vol 2010.

Thermal Technology LLC. 2010a, "Automatic Processing Furnace Systems." Vol 2010.

Thermal Technology LLC. 2010b, "Spark Plasma Sintering System." Vol 2010.

Utsunomiya, S and RC Ewing. 2006, "The Fate of the Epsilon Phase (Mo-Ru-Pd-Tc-Rh) in the $\mathrm{UO}_{2}$ of the Oklo Natural Fission Reactors." Radiochimica Acta 94:749-53.

Zhang, Y, H Li, PJ McGinn, B Yang, and BD Begg. 2008, "Stainless Steel/Glass-Ceramic Interactions under Hot Isostatic Pressing (HIPing) Conditions." Journal of Nuclear Materials 375:315-22. 


\section{Appendix A}

\section{TECHNIQUES THAT WERE NOT CONSIDERED}

In addition to the techniques mentioned above and examined in this report, there are several techniques that have been used in the literature for consolidation, for example consolidation in a host matrix, shockcompaction, etc. Some techniques have attractive attributes, such as the ability to achieve very high temperatures (plasma-spray and laser melting) that may be usable in waste consolidation process. However, these techniques have been deemed impractical owing to specific practical limitations and have not been considered in this report. These techniques have been briefly described here for completeness.

- Consolidation in a Host Matrix (e.g. cement, grout etc.)

- Shock Compaction

- Plasma-Spray

- Laser Melting

\section{A.1 Consolidation in a Host Matrix}

This method comprises a general class of techniques where the waste stream material is incorporated into a host matrix such as cement, grout, polymers etc. such that the host matrix primarily serves as a binder to the granular material. Of the various consolidation techniques examined in the report, this class of techniques are the simplest and easiest since they are carried out at room temperature. However, they have not been deemed as viable techniques for consolidating radioactive waste, because of corrosion and susceptibility to radiolysis effects. In the end, they do not decrease the exposed surface area for the $\varepsilon$ metal particles and do not consolidate the recycled metals from the aqueous process solutions.

\section{A.2 Shock Compaction}

Shock/dynamic compaction/consolidation of powders involves depositing intense amount of energy very rapidly ( microseconds) (Meyers 1994). Although the overall process may take place at roomtemperature, the passage of shock-waves through the granular material can raise the temperature significantly for brief moments that, combined with the intense shock pressures ( $\sim \mathrm{GPa})$, leads to sintering of powders. Therefore, it is an attractive technique to densify difficult-to-consolidate powders and ceramics. The shock energy may be produced with explosives, high-powered lasers, and high-velocity impacts, some of which are inappropriate for use in a hot cell. Owing to the highly specialized nature of shock-generation methods, this consolidation technique has very limited commercial availability and is mainly used for research purposes. Hence, shock compaction was not considered.

\section{A.3 Plasma Spray}

Plasma spray is a type of thermal spray process where powdered materials (metals, alloys, ceramics, etc.) are fed into a plasma stream and sprayed onto a substrate at high velocities. Temperatures within the core of the plasma may easily exceed $5000{ }^{\circ} \mathrm{C}$ that is sufficient to heat materials well above their melting point. This technique is primarily used for depositing coatings for protection against corrosion, environment, wear etc. This technique is attractive for waste consolidation from the point of view of its potential to melt the high-melting point phases expected in the waste stream and to achieve this melting in a small zone such that large furnaces/ovens are not required. Further, the plasma spray equipment is simple (plasma gun, electrical power supply and cooling water) that is easy to operate, can be turned on 
and off at will, and requires very little capital investment. The two disadvantages of this technique are the deposited layers crack/spall when the coating becomes thick and it is an inherently dusty process. Hence, it is not suitable for fabricating bulk, consolidated parts but rather more suited to depositing thin $(<\mathrm{mm})$ coatings. Further, the spray nozzle of the plasma gun requires the particle size of the raw materials to be within a narrow range and such tight size control may not be feasible in the incoming waste stream.

\section{A.4 Laser Melting/Sintering}

In this method, a high-powered focused laser (e.g. $\mathrm{CO}_{2}$ laser) is used to fuse powder into a solid by melting it locally. The sintered part is built up additively, layer by layer, based on information supplied by a computer aided design (CAD) file. This technique is primarily used for rapid prototyping where experimental designs and complex geometries can be manufactured in limited quantities for evaluation before deciding on the final geometry. This technique is attractive for waste consolidation process owing to the high energy density in the laser beam that may be sufficient to melt high-melting point oxides and other phases present in the waste stream. Since the melting and sintering takes place locally, there is no need of a container, thereby eliminating large furnaces/ovens and crucibles. However, the primary drawback of this method is that the sintered parts are typically porous and consequentially have high surface area - the very property we are trying to avoid. 